\title{
Andrew BERNSTEIN, Modern Passings. Death Rites, Politics and Social Change in Imperial Japan
}

Honolulu, Hawaii University Press, 2006, 242p.

\section{Fabienne Duteil-Ogata}

\section{(2) OpenEdition}

Journals

Édition électronique

URL : http://journals.openedition.org/assr/21517

DOI : $10.4000 /$ assr.21517

ISSN : 1777-5825

Éditeur

Éditions de l'EHESS

Édition imprimée

Date de publication : 31 décembre 2009

Pagination : $75-342$

ISBN : 978-2-7132-2218-4

ISSN : 0335-5985

Référence électronique

Fabienne Duteil-Ogata, « Andrew bernstein, Modern Passings. Death Rites, Politics and Social Change in Imperial Japan », Archives de sciences sociales des religions [En ligne], 148 | octobre-décembre 2009, document 148-19, mis en ligne le 27 janvier 2010, consulté le 21 septembre 2020. URL : http:// journals.openedition.org/assr/21517; DOI : https://doi.org/10.4000/assr.21517

Ce document a été généré automatiquement le 21 septembre 2020.

(C) Archives de sciences sociales des religions 


\section{Andrew BERNSTEIN, Modern Passings. Death Rites, Politics and Social Change in Imperial Japan}

Honolulu, Hawaii University Press, 2006, 242p.

Fabienne Duteil-Ogata

\section{RÉFÉRENCE}

Andrew BERNSTEIN, Modern Passings. Death Rites, Politics and Social Change in Imperial Japan, Honolulu, Hawaii University Press, 2006, 242p.

1 Andrew Bernstein, historien américain nous présente ici une étude portant sur une période charnière de l'histoire des funérailles au Japon: celle qui débute avec l'ère Meiji (1868-1912) et prend fin en 1945, la période du shintô d'État.

2 Basé sur un travail minutieux de dépouillement de la presse nationale et locale, des archives officielles et des archives des premières sociétés de pompes funèbres, A. Bernstein nous montre comment, durant cette période, les funérailles n'échappent pas au processus d'« invention de la tradition » selon les termes d'Eric Hobsbawm. En effet, la tradition persiste dans la nouveauté et la nouveauté passe souvent pour de la tradition. De même, comme dans tout pays industrialisé qui s'ouvre au monde occidental, l'influence extérieure est bien présente dans le traitement des morts à cette époque. À travers l'histoire des funérailles modernes, c'est un pan de l'histoire religieuse du Japon qui nous est conté, celle du shintô d'État qui veut imposer des funérailles shintô, c'est également en creux une histoire de la presse et l'avènement du débat public relayé par ce nouveau moyen de communication.

L'auteur commence par rappeler ce que sont les funérailles au Japon avant l'avènement de l'ère Meiji, c'est-à-dire des funérailles principalement prises en charge par l'institution bouddhique. En effet, la loi de 1671 a imposé aux familles japonaises de s'inscrire dans un temple bouddhique comme gage de non affiliation au christianisme. 
Cette obligation administrative, qui comprenait non seulement les déclarations d'état civil (naissance, mort et changement de résidence) a eu pour effet d'imposer progressivement les rituels funéraires bouddhiques et la constitution du système des familles paroissiennes bouddhiques danka seido qui institua une relation de dépendance financière et religieuse des familles vis-à-vis des monastères bouddhiques. Toutefois, la construction des tombes dans les monastères bouddhiques, qui marquait la pérennité de la filiation patrilinéaire de la famille, ne concernait à cette époque que les familles aristocratiques et les samouraïs.

4 Le bouddhisme offre une "vie après la mort ", notamment à travers le cycle de la réincarnation ou de l'accès à la bouddhéité pour ceux qui peuvent s'en affranchir. La crémation transforme le corps pollué en objet de révérence et les rites funéraires bouddhiques permettent de maintenir les liens patrilinéaires au sein de la famille élargie maison en effectuant le culte des ancêtres à travers des offrandes kuyô (fleurs, encens, lumière, nourriture) afin de pacifier le mort et le transformer en un ancêtre protecteur.

5 A. Bernstein montre comment le shintô, qui ne propose pas de discours et encore moins de dogme sur la vie après la mort, argue contre le bouddhisme pour proposer lui aussi des funérailles. Là encore, c'est dans la période de Tokugawa (1603-1868) que la pensée du shintô d'État commence à se formaliser, sous l'influence du modèle confucéen venu de Chine, bannissant notamment la crémation comme pratique défiant la piété filiale. Les premiers écrits qui tentent de fixer les pratiques funéraires shintô sont l'œuvre de Kanemi Yoshida (1531-1610) qui dirige le shintô Yoshida. Si les rituels reprennent des éléments du bouddhisme comme les offrandes d'encens, de fleurs et de nourriture, l'école Yoshida fait du mort un kami, (Inoue N., Kami : Arch., 108-52, 1999), une divinité shintô protectrice de la famille.

6 C'est pendant la restauration impériale, à l'ère Meiji (1868-1912), alors que les tenants du shintô ont la main mise sur le pouvoir et combattent hardiment le bouddhisme, que le shintô devient non seulement la religion d'État mais également la religion des funérailles.

7 Le nouveau ministère des rites déclare la séparation des kami et des bouddhas, alors que le Japon a toujours connu (depuis l'entrée du bouddhisme) un syncrétisme religieux, il oblige les desservants des sanctuaires shintô à procéder pour leurs familles à des funérailles shintô. Comme l'explique l'auteur, la difficulté à imposer des funérailles shintô pour tous réside dans le fait que la mort, état d'extrême pollution, est antinomique avec le culte des divinités shintô. En effet, les personnes en contact avec la mort doivent généralement s'éloigner des sanctuaires shintô ou des divinités pour des semaines, des mois voire une année pour éviter toute contamination. Ainsi, en 1872, le conseil d'État est-il obligé de légiférer par décret en stipulant que les personnes qui assistent à des funérailles shintô peuvent, le jour suivant l'office, effectuer un culte aux divinités shintô si elles procèdent aux rituels de purification. De même, les autorités nationales doivent également dissocier la pollution liée à la mort et au deuil, en fixant une durée de deuil identique pour tous. Le décret d'octobre 1874 indique alors que la période de deuil est un moment d'expression de la peine, arguant que ce processus est le même dans tous les pays développés.

8 Durant ces années 1870, le débat se focalise sur la nécessité, ou non, de la crémation. Bien que le bouddhisme, dans son dogme, ne privilégie aucune des quatre formes de traitement des sépultures (par la terre dosô, par l'eau suisô, par l'air/le vent fûsô, par le 
feu kasô), le fait que le bouddha historique Shâkyamuni ait été incinéré a eu pour effet, dès l'arrivée du bouddhisme au Japon, de généraliser la crémation pour les hauts dignitaires. La crémation a également une fonction pédagogique, nous dit l'auteur (p. 29) : celle d'illustrer la notion de l'impermanence de toute chose mûjo. Pourtant dans les années trente, un peu plus de la moitié des Japonais sont incinérés, alors que dans certaines régions, la crémation ne s'est popularisée que dans les années soixante-dix. Il s'agit donc d'un phénomène très récent qui prend de l'ampleur à la période moderne.

De 1873 à 1875, la crémation est interdite par le gouvernement qui trouvait cette pratique moralement condamnable à cause du traitement irrespectueux du corps humain (brûlé par les flammes) et également nocive pour la santé publique du fait de la pollution provoquée par les émanations toxiques des crématoriums. Lutter contre la crémation était pour les partisans du shintô lutter avant tout contre le bouddhisme, une religion importée. Les opposants arguent que la crémation est un procédé moderne (existant dans tous les pays civilisés, comme l'Angleterre, les États-Unis) et également hygiénique car les restes sont compacts, facilement transportables et occupent peu d'espace. Le problème de l'espace dans le cas de l'inhumation est pris très au sérieux par les autorités et ces différents points de vue font l'objet d'un débat public véhiculé par un nouveau média : la presse.

10 Cette période est également le théâtre d'un autre enjeu, celui de la liberté religieuse, concomitant à celui des funérailles. C'est en 1873 que le gouvernement de Meiji reconnaît officiellement le christianisme. La religion, nouveau concept venu d'Occident, ne semble pas correspondre à la réalité japonaise, mais dans un souci de se porter au même rang que les autres nations développées, le Japon doit reconnaître la liberté religieuse. Toutefois, comment reconnaitre le pluralisme religieux alors que le shintô devient peu à peu dans les faits une religion d'État? La réponse législative n'attend pas. En 1882, le gouvernement sépare définitivement le shintô des sanctuaires (shintô populaire) du shintô dites « des treize sectes » et souligne un point capital, le shintô des sanctuaires n'a pas de caractère religieux, contrairement à celui desdites sectes. En 1889, lorsque la constitution promulgue la liberté religieuse (article 28), il est alors aisé de confirmer le caractère officiel du shintô, dépouillé de son étiquette religieuse, transcendant le concept même de religion.

11 Cette institutionnalisation du shintô d'État ne fait pas que des heureux parmi les desservants shintô. Plusieurs pétitions demandent qu'ils n'aient pas l'obligation d'effectuer les rituels funéraires à cause de la pollution liée à la mort. Ils obtiennent gain de cause: le ministère de l'Intérieur promulgue un décret interdisant aux officiants shintô de haut rang de procéder aux rituels funéraires, tout en laissant le soin, au nom de la liberté religieuse, aux autres desservants de procéder ou non aux funérailles.

De même, en ce qui concerne les tombes, il n'était pas possible de construire des tombes shintô pour l'ensemble de la population, même si le projet émis en 1874 permet la construction des premiers cimetières publics municipaux. À cette époque également, les premières lois relatives aux tombes, (tailles, distance de l'habitation, etc.) voient le jour. L'influence occidentale semble effective dans la construction de ces nouveaux cimetières municipaux qui, faute d'espace, sont implantés en périphérie des villes et ressemblent plutôt à des parcs où arbres et arbustes sont plantés afin de créer une atmosphère paisible et agréable. 
13 Cette période voit également l'avènement des sociétés de pompes de funèbres qui s'adaptent à la demande des clients et aux nouvelles technologies. Dans les années trente, la procession laisse peu à peu place au corbillard et les cérémonies ont lieu de plus en plus souvent au domicile de la famille plutôt qu'au monastère. De nombreux dispositifs de sociétés de pompes funèbres, toujours effectifs actuellement, se mettent en place à cette époque. Rappelons également l'étude de $\mathrm{H}$. Suzuki sur ces sociétés de pompes funèbres contemporaines (The Price of Death. The Funeral Industry in Contemporary Japan: Arch., 132-65, 2005). L'auteur y montre qu'au début des années vingt, plusieurs intellectuels utilisent la presse pour exprimer publiquement leur réserve quant à l'efficacité des rituels, préférant pour certains donner leur corps à la science, voulant briser les conventions sociales et religieuses. Ces questions sont toujours d'actualité comme le signale A. Bernstein dans son dernier chapitre intitulé "The Japanese way of death and its critics ».

14 Ouvrage historique d'une grande richesse, il s'adresse préférentiellement aux spécialistes des religions japonaises ou de l'ère Meiji, mais l'approche comparative amorcée à plusieurs reprises avec les pays anglo-saxons destine cet ouvrage à un plus large public. 